\title{
Preoperative pregnancy testing
}

\author{
Janae L Maher MD, Raman C Mahabir MD MSc FRCSC FACS
}

\author{
JL Maher, RC Mahabir. Preoperative pregnancy testing. Can J Plast \\ Surg 2012;20(3):e32-e34.
}

BACKGROUND: In up to $2 \%$ of all pregnancies, the need for general anesthesia in a nonobstetrical surgery arises. Surgery on a pregnant woman may have significant implications for the fetus, patient, physician and hospital. On review of the plastic surgery literature, the authors were unable to find current guidelines or recommendations for preoperative pregnancy testing in the plastic surgery patient population.

METHODS: Literature regarding maternal and fetal risk during anesthesia and surgery, as well as preoperative pregnancy testing was identified by performing a PubMed, OVID and MEDLINE key word search. The current literature was subsequently reviewed and summarized.

RESULTS: A report by the American Society of Anesthesiologists Task Force on Preanesthesia Evaluation allows physicians and hospitals to implement their own policies and practices with regard to preoperative pregnancy testing. The overall frequency of an incidentally found positive preoperative pregnancy test ranges from $0.34 \%$ to $2.4 \%$.

DISCUSSION: Various studies have reported increased rates of spontaneous abortions, congenital anomalies, such as neural tube defects, and low and very low birth weight infants born to mothers exposed to anesthesia and surgery during pregnancy. Because the accepted practice is to postpone elective surgery during pregnancy, identifying these patients before surgery is critical.

CONCLUSIONS: Based on the current evidence, the authors' best practice recommendation for preoperative pregnancy testing is provided.

Key Words: Anesthesia; Pregnancy testing; Preoperative assessment; Surgery during pregnancy

Surgery on a pregnant woman may have significant implications for $\checkmark$ the fetus, patient, physician and hospital. On review of the literature, we were unable to find current guidelines or recommendations for preoperative pregnancy testing in the plastic surgery patient population. This prompted us to review the current literature and develop a best practice recommendation.

\section{FETAL RISK OF ANESTHESIA AND SURGERY}

In the United States, more than 75,000 pregnant women undergo nonobstetrical surgery each year. This means that in up to $2 \%$ of all pregnancies, the need for general anesthesia arises (1-3). It is commonly recommended that all surgery, unless truly emergent, be postponed until after delivery to minimize the risk to the fetus. Organogenesis occurs during the first trimester. In the third trimester, there is a higher risk of premature labour. Waiting is best; however, if absolutely necessary, the second trimester is typically regarded as the safest time period for performing surgical procedures (1).

Various studies have attempted to more accurately assess the hazards and risks of administration of anesthesia and of surgery during gestation. Virtually every inhalational anesthetic and drug is teratogenic to some species or another at some point in gestation under certain conditions. However, none of these agents have yet to be classified as an absolute human teratogen (1). The potential teratogenic effects of drugs administered and risk of premature labour, maternal hypoxia and/or acidosis, and alterations in uteroplacental blood flow during surgery definitely exist and pose a distinct hazard to the fetus.

\section{Des tests de grossesse préopératoires}

HISTORIQUE : Dans jusqu'à $2 \%$ de toutes les grossesses surgit la nécessité d'une anesthésie générale en vue d'une opération non obstétricale. L'opération d'une femme enceinte peut avoir des conséquences importantes pour le fœetus, la patiente, le médecin et l'hôpital. À l'analyse de la documentation en chirurgie plastique, les auteurs n'ont pu trouver de lignes directrices ou recommandations à jour sur les tests de grossesse préopératoires auprès de la population de patientes subissant une chirurgie.

MÉTHODOLOGIE : Les auteurs ont colligé la documentation scientifique à l'égard du risque pour la mère et le foetus pendant l'anesthésie et des tests de grossesse préopératoires au moyen d'une recherche par mots clés dans PubMed, OVID et MEDLINE. Ils l'ont ensuite analysée et résumée. RÉSULTATS : Un rapport du groupe de travail sur l'évaluation préanesthésique de l'American Society of Anesthesiologists permet aux médecins et aux hôpitaux d'adopter leurs propres politiques et pratiques relativement aux tests de grossesse préopératoires. La fréquence globale de tests de grossesse préopératoires dont les résultats positifs sont fortuits oscille entre $0,34 \%$ et $2,4 \%$.

EXPOSÉ : Diverses études font état d'une augmentation du taux d'avortements spontanés, d'anomalies congénitales, telles qu'une anomalie du tube neural, et de petit poids ou d'extrême petit poids de naissance chez les nourrissons nés de mères exposées à l'anesthésie et à la chirurgie pendant la grossesse. Puisqu'en cas de grossesse, la pratique acceptée consiste à reporter les chirurgies non urgentes, il est essentiel de repérer ces patientes avant l'opération.

CONCLUSIONS : D'après les données probantes actuelles, les auteurs présentent leurs recommandations de pratique exemplaire à l'égard des tests de grossesse avant une opération.

In 1963, the first reported study identified 67 operative cases during pregnancy out of 18,248 patients (2) $(0.36 \%$ operative rate). Only 24 of these patients received general anesthesia and five were in the first trimester. With such a small patient population and no control group, detailed analyses were not performed, but an overall fetal mortality rate of $15 \%$ was reported. A later study by Shnider and Webster (3) in 1965 examined a series of 147 operations involving 9073 pregnant women (1.62\% operative rate). Perinatal mortality and low birth weight were increased; however, when the patients who underwent cerclage procedures were removed from the analyses, the findings were no longer statistically significant. In 1980, Brodsky et al (4) examined fetal outcomes after surgery during pregnancy by surveying 12,929 dental assistants and dentists' wives. A total of 187 women were identified as having had surgery in the first trimester and 100 women in the second trimester (2.22\% operative rate). They found that women who underwent surgery in the first and second trimesters experienced significantly higher rates of spontaneous abortions than controls. Duncan et al (5) compared 2565 pregnant women undergoing surgery with control pregnant women not undergoing surgery in 1986. They also found that anesthesia and surgery in the first and second trimester were associated with an increased risk of spontaneous abortion.

Mazze and Kallen (6) reported the largest series to date in 1989, reviewing a Swedish registry with 5405 cases in 720,000 births $(0.75 \%$ operative rate). They found that the incidences of low $(<2500 \mathrm{~g})$ and very low birth weight $(<1500 \mathrm{~g})$ infants born to mothers who underwent surgery during pregnancy were increased. Premature birth in this patient population was increased by $46 \%$. Their outcome data also

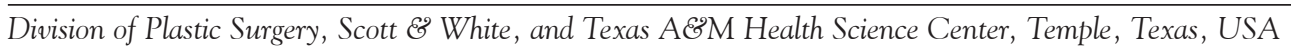

Correspondence: Dr Raman C Mahabir, Division of Plastic Surgery, Scott $\mathcal{E}$ White Healthcare, 2401 South 31st Street, Temple,

Texas 76508, USA. Telephone 254-724-2321, fax 254-724-0315, e-mail rmahabir@swmail.sw.org 
showed that infants who were born alive had a greater than expected mortality rate within seven days of birth. Consistent with previous studies, they did not find an increase in congenital anomalies (2-6). However, in 1990, on further examination of the original data, Kallen and Mazze (7) detected an unusually large number of neural tube defects (NTDs). This was particularly prominent when the anesthesia and surgery exposure occurred during gestational weeks four to five, the time period of neural tube formation, suggesting a causal link. In 1994, Sylvester et al (8) explored this further by reporting a case-control study that examined mothers of control infants and mothers of infants with NTDs, and assessed exposure to anesthesia and surgery in the first trimester. Exposure in the first trimester was found to have the strongest association with hydrocephalus and other major defects (OR 9.6 [95\% CI 3.8 to 24.6]), most commonly eye defects (OR 39.6 [95\% CI 7.5 to 209.2]).

Aside from the previously discussed risks of anesthesia and surgery in the pregnant patient, undergoing an operative procedure in general may expose the fetus to potentially harmful insults. Perioperative drugs, such as topical nasal administration of cocaine, antibiotics, analgesics, nonsteroidal anti-inflammatory drugs, antiarrhythmics or newer drugs with unknown safety profiles may be required (3). Pre- or postoperative films or intraoperative fluoroscopy may expose the fetus to ionizing radiation, for which there is a known increased risk of congenital anomalies, especially in the first trimester (9).

\section{PREOPERATIVE PREGNANCY TESTING}

The purpose of performing preoperative laboratory testing is to gain pertinent information about the patient that, if abnormal, would influence the plan of care. Otherwise, these tests would be unnecessary and contribute only to increased costs and operative delays. Determining pregnancy based solely on history and physical examination alone can prove to be difficult $(10,11)$. Because accepted practice is to postpone elective surgery during pregnancy, identifying these patients before surgery is critical, especially in the early phase of gestation when it is often unrecognized by the patient and physician, and the risks to the fetus are the greatest. Preoperative pregnancy testing, therefore, appears to play a key role in ensuring that both the patient and physician have the opportunity to make a more informed decision with respect to surgical plans.

In a prospective study performed by Manley et al (10), 2056 women of childbearing age underwent preoperative pregnancy testing when presenting for nonobstetrical, ambulatory surgery. They reported an incidence of $0.34 \%$ previously unrecognized early pregnancies, all of which resulted in cancellation or postponement of the procedure. Azzam et al (12) reported the results of their institution's mandatory preoperative pregnancy testing in 412 adolescents, a patient group known to be reluctant to disclose sexual history or pregnancy status. No patient 14 years of age or younger tested positive; however, there was an incidence of $2.4 \%$ in patients 15 years of age or older. The overall incidence was calculated to be $1.2 \%$. Similarly, Twersky and Singleton (11) reported a positive pregnancy rate of $2.2 \%$ on preoperative testing.

The cost-benefit ratio of preoperative pregnancy testing is a very difficult value to assess and quantify. A few studies have published hospital costs of performing routine preoperative pregnancy testing. Manley et al (10) reported a cost of $\$ 2,879$ per pregnancy identified. It is unclear how this compares with an unknown - but very real - potential cost of an unfortunate maternal-fetal event associated with not testing. In the first trimester, up to $50 \%$ of unrecognized pregnancies spontaneously abort and, of known pregnancies, there is a $15 \%$ spontaneous abortion rate before 20 weeks gestation (13). Cause and effect is difficult to determine; however, should a miscarriage occur after anesthesia and surgery exposure, or should the child have a congenital anomaly at birth, the patient, physician and hospital may be placed in an unfortunate scenario that could have been avoided with simple preoperative testing. In fact, Kahn et al (13) reported their results after implementing a policy of preoperative testing in elective orthopedic

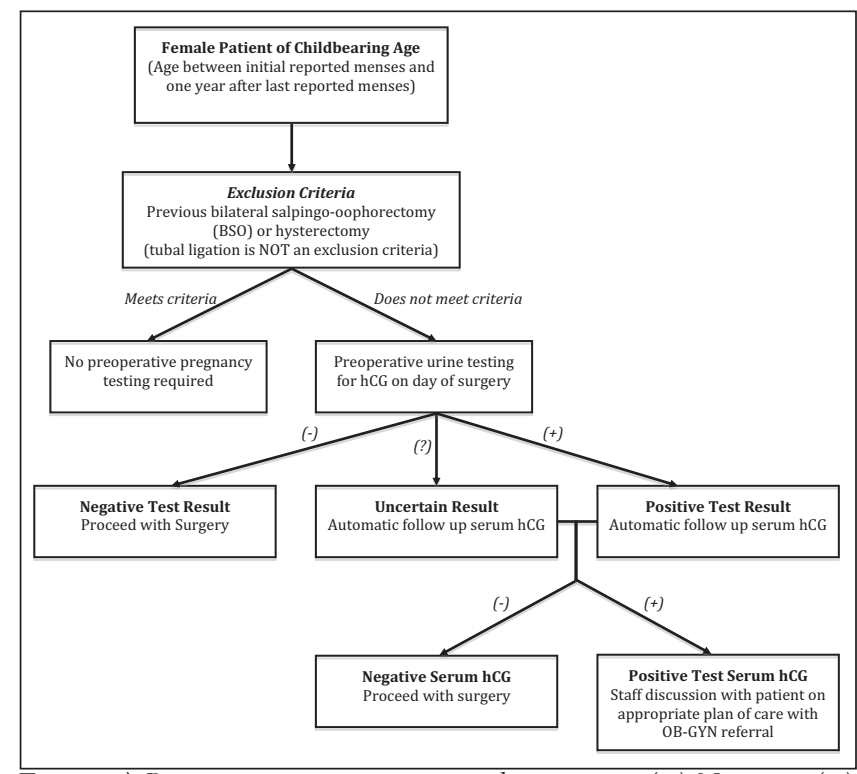

Figure 1) Preoperative pregnancy testing decision tree. (-) Negative; (+) Positive; hCG Human chorionic gonadotropin; OB-GYN Obstetriciangynecologist

procedures. They found the number needed to treat was 647 to detect one true positive result, with a cost of $\$ 3,273$ per true positive. In the first year of testing, two women experienced miscarriages after cancellation of their surgery secondary to a positive urine test and, therefore, the dreaded medicolegal scenario described above was avoided. A third patient with previous tubal ligation was found to have an ectopic pregnancy after a preoperative positive test result, thus avoiding a potentially devastating complication of rupture.

A report by the American Society of Anesthesiologists Task Force on Preanesthesia Evaluation (14) did not find enough sufficiently rigorous current literature to assess the benefits or harms of routine versus selected preoperative testing, or the timing of such tests. Routine preoperative pregnancy testing refers to testing all premenopausal menstruating females preoperatively without exclusions based on patient history. It advises that preanesthesia pregnancy testing, "may be considered for all female patients of childbearing age," essentially allowing physicians and hospitals to implement their own policies and practices with regard to this.

\section{DISCUSSION}

Based on the present literature review, our division implemented a preoperative pregnancy testing protocol as part of a quality assurance initiative in an attempt to optimize our patient and physician's informed decision making, to improve risk management and to enhance patient safety (Appendix A). Beginning January 1, 2011, all female patients of childbearing age (defined as the age between initial reported menses and one year after final reported menses) undergoing plastic surgery procedures and not meeting exclusion criteria will undergo preoperative urine testing for human chorionic gonadotropin (hcG) on the day of surgery. All uncertain negative and positive results will be discussed with the patient by the attending physician and subsequently followed by serum hCG testing automatically. Patients with a negative serum test may proceed with surgery as scheduled; whereas patients with a positive serum hCG will be referred to their obstetrician-gynecologist for consultation and follow-up care. Reasons for exclusion include patient report of bilateral salpingo-oophorectomy or hysterectomy (tubal ligation is NOT an exclusion criteria) and patient refusal; however, it will be up to the surgeon's discretion as to whether to proceed with the surgery if the patient refuses testing (Figure 1).

It is our belief that although conflict in the literature still exists on whether routine or selective testing should be performed and the timing of such tests, the critical point is to establish and apply a 
preoperative pregnancy testing protocol, approved by the hospital staff and followed in all situations. Simply having a consistent policy in place is the best evidence of an appropriate standard of care, especially when there is still some debate on the subject. Future investigations on the outcome of the implementation of our division's preoperative pregnancy testing policy are planned.

\begin{tabular}{|c|c|}
\hline $\begin{array}{l}\text { APPENDIX A } \\
\text { SCOTT \& WHITE PREOPERATIVE PREGNANCY } \\
\text { TESTING POLICY } \\
\text { SCOTT \& WHITE MEMORIAL HOSPITAL } \\
\text { DEPARTMENT OF SURGERY } \\
\text { DIVISION OF PLASTIC SURGERY } \\
\text { Preoperative Pregnancy Testing in Plastic Surgery } \\
\text { Patients } \\
\text { TOPIC: } \\
\text { DIVISION: Plastic Surgery } \\
\text { I. POLICY: This policy will guide preoperative pregnancy testing } \\
\text { for female patients of child bearing age (defined as the age } \\
\text { between initial reported menses and one year after last reported } \\
\text { menses) undergoing plastic surgery procedures. } \\
\text { II. SCOPE: Preoperatively, all female patients of child bearing age } \\
\text { undergoing plastic surgery procedures and not meeting exclusion } \\
\text { criteria will undergo urine testing for hCG on the day of surgery. } \\
\text { All uncertain negative and positive results will be discussed with } \\
\text { the patient by the attending physician and then followed by } \\
\text { serum hCG testing automatically. Those with a negative serum } \\
\text { test may proceed with surgery as scheduled; whereas patients } \\
\text { with a positive serum hCG will be referred to their OB-GYN for } \\
\text { consultation and follow-up care. } \\
\text { III. REASONS FOR EXCLUSION OF TESTING: } \\
\text { - Patient report of hysterectomy or bilateral salpingo- } \\
\text { oophorectomy (BSO). Tubal ligation is NOT an exclusion } \\
\text { criteria. } \\
\text { discretion as to whether or not to proceed with the surgery. }\end{array}$ & $\begin{array}{l}\text { REFERENCES } \\
\text { 1. Kuczkowski KM. Nonobstetric surgery during pregnancy: What are } \\
\text { the risks of anesthesia? Obstet Gynecol Surv 2004;59:52-6. } \\
\text { 2. Smith BE. Fetal prognosis after anesthesia during gestation. } \\
\text { Anesth Analg 1963;42:521-6. } \\
\text { 3. Shnider SM, Webster GM. Maternal and fetal hazards of surgery } \\
\text { during pregnancy. Am J Obstet Gynecol 1965;92:891-900. } \\
\text { 4. Brodsky JB, Cohen EN, Brown BW, Wu ML, Whitcher C. } \\
\text { Surgery during pregnancy and fetal outcome. Am J Obstet Gynecol } \\
\text { 1980;138:1165-7. } \\
\text { 5. Duncan PG, Pope WDB, Cohen MM, Greer N. Fetal risk of } \\
\text { anesthesia and surgery during pregnancy. Anesthesiology } \\
\text { 1986;64:790-4. } \\
\text { 6. Mazze RI, Kallen B. Reproductive outcome after anesthesia and } \\
\text { operation during pregnancy: A registry study of 5405 cases. } \\
\text { Am J Obstet Gynecol 1989;161:1178-85. } \\
\text { 7. Kallen B, Mazze RI. Neural tube defects and first trimester } \\
\text { operations. Teratology 1990;41:717-20. } \\
\text { 8. Sylvester GC, Khoury MJ, Lu X, Erickson JD. First-trimester } \\
\text { anesthesia exposure and the risk of central nervous system defects: } \\
\text { A population-based case-control study. Am J Public Health } \\
\text { 1994;84:1757-60. } \\
\text { 9. Swartz HM, Reichling BA. Hazards of radiation exposure for } \\
\text { pregnant women. JAMA 1978;239:1907-8. } \\
\text { 10. Manley S, de Kelaita G, Joseph NJ, Salem R, Heyman HJ. } \\
\text { Preoperative pregnancy testing in ambulatory surgery. } \\
\text { Anesthesiology 1995;83:690-3. } \\
\text { 11. Twersky RS, Singleton G. Preoperative pregnancy testing: } \\
\text { Justice and testing for all. Anesth Analg 1996;83:438-9. } \\
\text { 12. Azzam FJ, Padda GS, DeBoard JW, Krock JL, Kolterman SM. } \\
\text { Preoperative pregnancy testing in adolescents. Obstetric Anesthesia } \\
\text { 1996;82:4-7. } \\
\text { 13. Kahn RL, Stanton MA, Tong-Ngork S, Liguori GA, Edmonds CR, } \\
\text { Levine DS. One-year experience with day-of-surgery pregnancy } \\
\text { testing before elective orthopedic procedures. Ambulat Anesthesiol } \\
\text { 2008;106:1127-31. } \\
\text { 14. American Society of Anesthesiologists Task Force on PreAnesthesia } \\
\text { Evaluation. Practice advisory for pre anesthesia evaluation: A report } \\
\text { by the American society of anesthesiologists task force on pre } \\
\text { anesthesia evaluation. Anesthesiology 2002;96:485-96. }\end{array}$ \\
\hline
\end{tabular}

We reviewed the literature on maternal and fetal risk during anesthesia and surgery, as well as on preoperative pregnancy testing. Based on the current evidence, our best practice recommendation for preoperative pregnancy testing is provided.

\section{REFERENCES}

the risks of anesthesia? Obstet Gynecol Surv 2004;59:52-6.

during pregnancy. Am J Obstet Gynecol 1965;92:891-900.

Mazze RI, Kallen B. Reproductive outcome after anesthesia and anesthesia exposure and the risk of central nervous system defects: 1994:84:1757-60.

Azzam FJ, Padda GS, DeBoard JW, Krock JL, Kolterman SM. 1996;82:4-7

Kahn RL, Stanton MA, Tong-Ngork S, Liguori GA, Edmonds CR, 2008;106:1127-31

American Society of Anesthesiologists Task Force on PreAnesthesia by the American society of anesthesiologists task force on pre 